\title{
Wireless Last Mile Study in Rural Areas
}

\author{
Bagus Aditya $^{1^{*}}$, Galih Nugraha Nurkahfi ${ }^{2}$, Christoporus Ivan Samuels ${ }^{3}$ \\ ${ }^{1}$ Universitas Telkom \\ Jl. Telekomunikasi Jl. Terusan Buah Batu, Sukapura, Kec. Dayeuhkolot, Bandung \\ ${ }^{2}$ Lembaga Ilmu Pengetahuan Indonesia \\ Jl. Sangkuriang, Komplek LIPI Gd. 20, Jl. Cisitu Lama, Dago, Coblong, Bandung \\ ${ }^{3}$ Institut Teknologi Bandung \\ Jl. Ganesa No.10, Lb. Siliwangi, Coblong, Bandung \\ goesaditya@telkomuniversity.ac.id ${ }^{1 *}$, galih.nugraha.nurkahfi@lipi.go.id ${ }^{2}$, ivan@stei.itb.ac.id ${ }^{3}$
}

\begin{abstract}
Internet access has become a primary human need. During the COVID 19 pandemics, almost all activities such as studying and working online. However, several rural areas still did not have internet access due to weak cellular signals. Internet access in rural areas can have various alternatives, such as VSAT (satellite). It needs an inexpensive and precise way to complete the internet access coverage because many customers were concentrated in areas far from the VSAT terminal. WLAN 802.1 In was an alternative way to expand the range of internet coverage with low cost and easy implementation. Our case study uses the $5 \mathrm{GHz}$ frequency with a sectoral antenna as the multi-hop point-to-point backhaul network's frequency to avoid the risk of channel interference on the backhaul. On the other hand, $2.4 \mathrm{GHz}$ frequency with an omnidirectional antenna serves smartphone customers. On the test results, the network latency between multihop access point, has a maximum value of 19,894 ms. This result means that the latency obtained can be categorized as preferred VoIP services based on ITUT G.1010 in the local network. Then for the customer on the fourth hop, 3968 meters from the VSAT terminal, the UDP data rate of 1.04Mbps was stable, and the TCP data rate decreased to 1.26Mbps. This paper emphasizes the use of multihop $5 \mathrm{Ghz}$ WLAN 802.11n as a backhaul to expand internet access coverage from VSAT in rural areas, where the concentration of customers was far apart and there were many buffalo horn barriers in traditional homes and buildings.
\end{abstract}

Keywords: vsat, multi-hop wireless, rural internet, backhaul.

\section{Introduction}

In line with the demand for internet access in rural areas, the need for coverage and internet access capacity also increases. If the internet provider uses a VSAT terminal for each customer, it will cause an expensive investment. Customers in rural areas are spread out quite far and varied. Houses between residents are usually located quite far from other places. That is why the potential revenue in rural areas is relatively low [1].

WLAN 802.11n network as backhaul network using $5 \mathrm{GHz}$ unlicensed spectrum could be an alternative solution [2]. This solution will be easy to deploy because WLAN 802.11n Access Point with $5 \mathrm{GHz}$ frequency is now readily available in the market at affordable prices. The use of unlicensed spectrum makes deployment more manageable and reduces investment costs because there is no need to pay frequency usage fees.

However, this solution is better than using $2.4 \mathrm{GHz}$ frequency as the backhaul network, where there are so many co-channel interferences by existing Access Point in the study case location. Based on the considerations mentioned above, a design trial that focuses on analyzing the feasibility of an 802.11n WLAN solution for internet access extension coverage is needed. This case study will use a multi-hop topology point-to-point backhaul WLAN 802.11n network at a $5 \mathrm{Ghz}$ frequency. The challenges faced in designing the network in this case study are the location of the concentration of customers far from each other, different contours of the earth, the presence of obstacles in houses and buildings that use buffalo horn (Gadang house). This paper emphasizes

TELKA, Vol.7, No.2, November 2021, pp. 100 107

ISSN (e): 2540-9123

ISSN (p): 2502-1982 
the use of multihop 5Ghz WLAN 802.11n as a backhaul to expand internet access coverage from VSAT in rural areas, where the concentration of customers is far apart and there are many buffalo horn barriers in homes and buildings.

\section{Methodology}

\subsection{Literature Study}

\subsubsection{WLAN Technology}

Wireless technologies use electromagnetic waves in the air to send and receive information. For several applied sciences to simultaneously use these electromagnetic waves, the wireless spectrum is divided into frequency bands. The usage of a licensed frequency band is obliged to pay a license fee for the unique right to transmit on the frequency band channel. Licensing is a way of making sure that wireless frequency customers do not interfere with other wireless devices. Without a license, everyone can use the frequency band so that data transmission requests will have terrible performance [3].

On the other hand, an unlicensed frequency band does not require any permission. The product and usage comply with the policies associated with that unlicensed frequency band (for example, the maximum power transmission). But unlicensed wireless technology is susceptible to interference. That is why WLANs in your home or workplace can have signal degradation caused by another WLAN device working on the equal channel in the 2.4 or $5 \mathrm{GHz}$ band [4].

Propagation in wireless communication is when communication indicators are transmitted using electromagnetic waves from one point to another in the open air. Ideal propagation can happen if the waves emitted by the transmitting antenna are directly received by receiving antenna without going via a barrier (Line of Sight/LOS). Electromagnetic waves' characteristics consist of various types, particularly reflection, diffraction, absorption, polarization, and scattering. Propagation at the unlicensed $2.4 \mathrm{GHz}$ frequency is in a similar way defined in nearly all countries, namely in the $2.4 \mathrm{GHz}$ to $2.485 \mathrm{GHz}$ frequency range. These similarities make WLAN implementation easier and cheaper. Based on the 802.11 WLAN implementation standard, it is possible to use $20 \mathrm{MHz}$ width channels on channels 1,6 , and 11 without overlapping each other.

Meanwhile, the propagation of $5.8 \mathrm{GHz}$ allows greater bandwidth due to the number of available spectrum [5]. However, the propagation distance turns shorter at this frequency because the attenuation will increase with the frequency. At this frequency, it is feasible to put into effect countless access points that are close to each different to function on non-overlapping channels. Some get admission to factors that can operate on two channels to serve countless customers with one-of-a-kind channels and good throughput.

\subsubsection{WLAN Backhaul Network Theory}

Some theoretical considerations can be used in measuring and designing WLAN networks for backhaul [6]:

a. Free space loss propagation attenuation, with Line-of-sight prerequisites and an isotropic antenna, $\mathrm{L}=32.5+20 \log \mathrm{f}(\mathrm{MHz})+20 \log \mathrm{d}(\mathrm{km}) \mathrm{Db}$

b. Plane Earth Path Loss, or attenuation caused by propagation when the earth is considered as a flat plane, $\mathrm{L}=40 \log \mathrm{d}(\mathrm{m})-20 \log \mathrm{hT}(\mathrm{m})-20 \log \mathrm{hg}(\mathrm{m}) \mathrm{Db}$ as shown in Figure 1 .

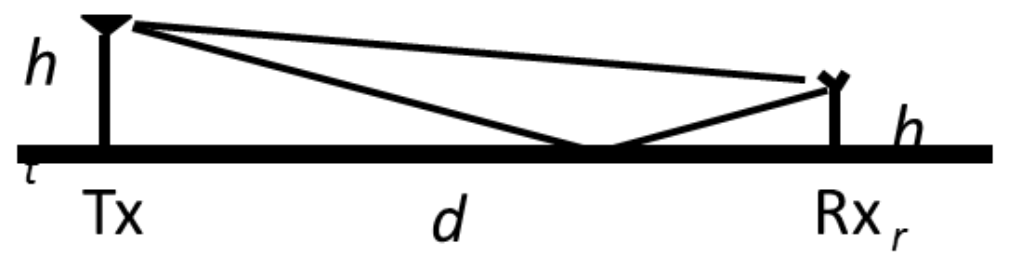

Figure 1. Plane earth path loss. 
c. The receiver's signal will experience a loss caused by the barrier's reflection is called diffraction loss.

d. Fresnel zone is an area on a microwave transmission path depicted in the form of an ellipse that shows electromagnetic wave interference if there is blocking.

\subsubsection{WLAN Access Network Theory}

Calculations using the Okumura-Hata model are used to determine the radius of WLAN access point coverage based on its transmission power and the device's antenna gain. The Okumura-Hata model can predict additional attenuation of free space loss based on the height of the transmitting and receiving antennas, the distance between sender and receiver, signal frequency, and area type [6].

The Okumura model itself applies to $150-1920 \mathrm{MHz}$ (extrapolated up to $3000 \mathrm{MHz}$ ), ranges from 1 to $100 \mathrm{~km}$, and antenna heights from 30 to $1000 \mathrm{~m}$. The Okumura model produces an error deviation between measurement and prediction of 10-14 dB.

The formulation of the Okumura model itself can be shown as follows:

$$
L(d B)-L_{F}+A_{u}-G\left(h_{t e}\right)-G\left(h_{r e}\right)-G_{\text {Area }}
$$

Note:

$L_{F}=$ Free Space Loss

$A_{u}=$ Attenuation

$G\left(h_{t e}\right)=A P$ antenna height factor

$G\left(h_{r e}\right)=M S$ antenna height factor

$G_{\text {Area }}=$ Gain Area

Besides using the Okumura model, the Hata model is also widely used as an empirical model of the Okumura chart and is valid for $150-1500 \mathrm{MHz}$ frequencies. The Hata model is efficient and results very close to the Okumura curve for distances $>1 \mathrm{~km} \mathrm{[6].} \mathrm{The} \mathrm{primary} \mathrm{formulation} \mathrm{of}$ attenuation for the type of urban area using the Hata model is as follows: Note :

$$
L_{U}=69,55+26,16 \log f-13,2 \log h_{t e}-a\left(h_{r e}\right)+\left(44,9-6,55 \log h_{t e}\right) \log d[d B]
$$

$f=$ frekuensi $(\mathrm{MHz})$

$h_{t e}=$ AP antenna height $(30-200 \mathrm{~m})$

$h_{r e}=M S$ antenna height $(1-10 \mathrm{~m})$

$d=$ distance of $T_{x}-R_{x}(\mathrm{~km})$

$a\left(h_{r e}\right)=$ MS antenna correction factor

\subsection{Design Network Topology}

Design of the network's topology can be seen in Figure 2.

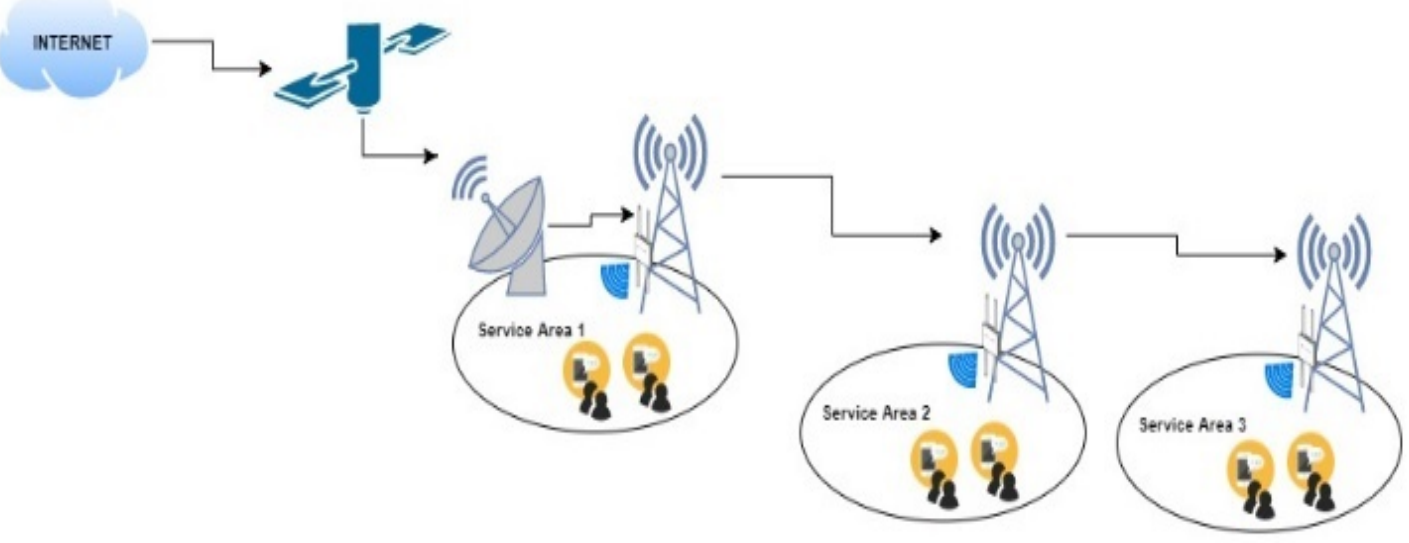

Figure 2. Design multihop network topology. 
Internet access from VSAT received by the ground station. VSAT modem in the ground station will forward the internet access to the $2.4 \mathrm{GHz}$ ground access point (Service Area 1) and $5 \mathrm{GHz}$ backhaul access point (Hop 1). At the first hop, the backhaul access point will extend the service to the second hop backhauls $5 \mathrm{GHz}$ access point. The second Hop backhaul access point (AP receiver) will forward data to the switch device. The switch will bridge the network to a $2.5 \mathrm{GHz}$ ground access point at service area 2, and the second hop AP transmitter transmits the signal to the next hop, and so on. There will be two 5GHz sectoral Access Point (receiver and transmitter) in the middle of the hop as the backhaul, then one $2.4 \mathrm{GHz}$ ground access point to serve the service area at each hop. Below the specification of the used device:

1. The backhaul AP use Ubiquity Nanostation Loco M5 $5 \mathrm{GHz} 802.11 \mathrm{n}$ Antenna $13 \mathrm{dBi}$, Power $23 \mathrm{dBm}$ [5].

2. The ground AP use Ubiquity Bullet M2 $2.4 \mathrm{GHz}$.

\subsection{P2P Link Calculation}

The choice of test field location is determined to be at a City in west Sumatra with the following considerations:

1. Information on the availability of telecommunication towers

2. Geographical conditions can represent rural areas

The test field is known to consist of the following geographical conditions composition:
a. 2,771.11 (Ha) of paddy land,
b. 2,034.08 (Ha) of land and surrounding buildings,
c. $194.06(\mathrm{Ha})$ Pond / pond,
d. 1,639.65 (Ha) Garden / field land,
e. $364.50(\mathrm{Ha})$ Forest,
f. $43.20(\mathrm{Ha})$ Pasture and
g. $996.56(\mathrm{Ha})$ Bushes and others.

WiFi PtP link calculator for backhaul in this study uses tool on the vendor's website at https://link.ui.com/. In this tool, WiFi transmitters and receivers are placed at five sites according to the concept of testing with tower height that has been adjusted to field conditions, namely at site A, site B, site C, and site D. The ground contours between sites can be seen in Figure 3 - 5 . This calculation aims to determine how the profile of the earth's contours at each link between sites and its effect on the transmit power of the signal in each device using the concepts of free space loss and Fresnel zone. This calculation uses same vendor devices with the nearest specifications for field testing. The selected calculation device uses a $5 \mathrm{GHz}$ frequency with $1.3 \mathrm{Gbps}$ throughput, $29 \mathrm{dBm}$ output power with 9dBi Antenna Gain.

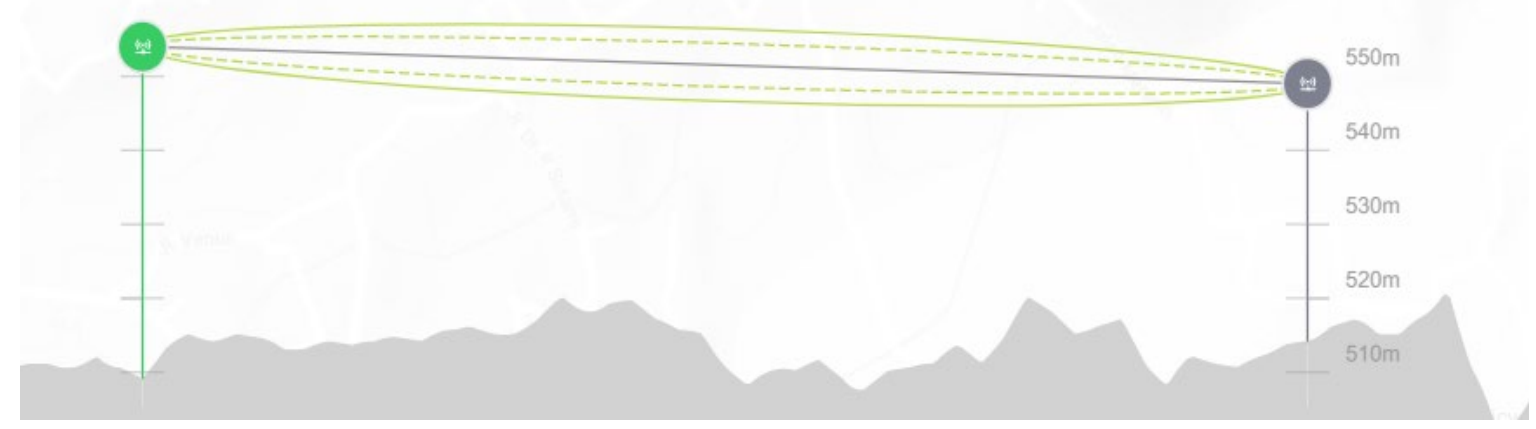

Figure 3. Ground contour site A - site B. 


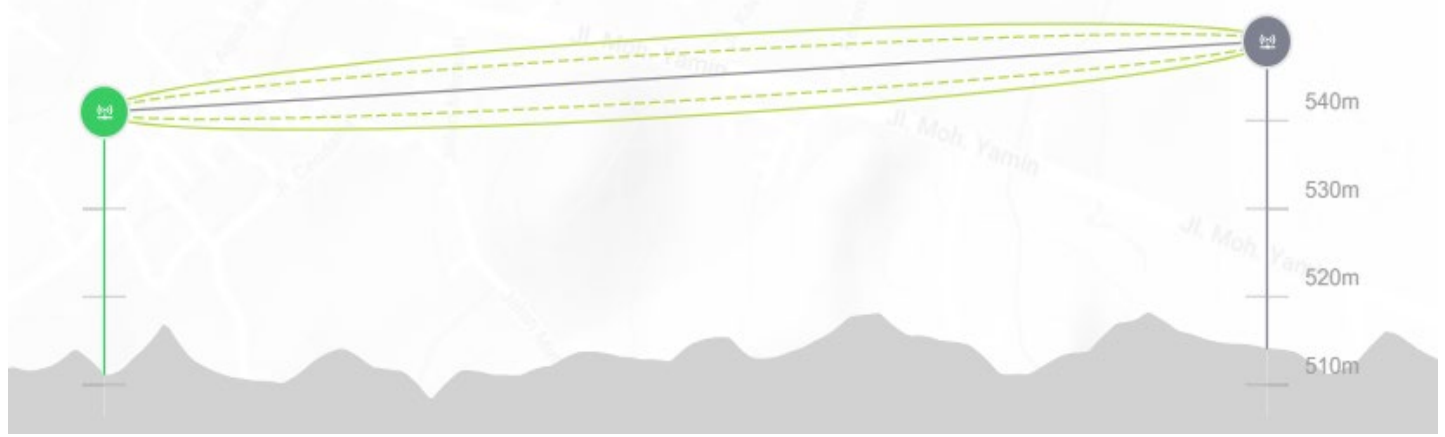

Figure 4. Ground contour site B - site C.

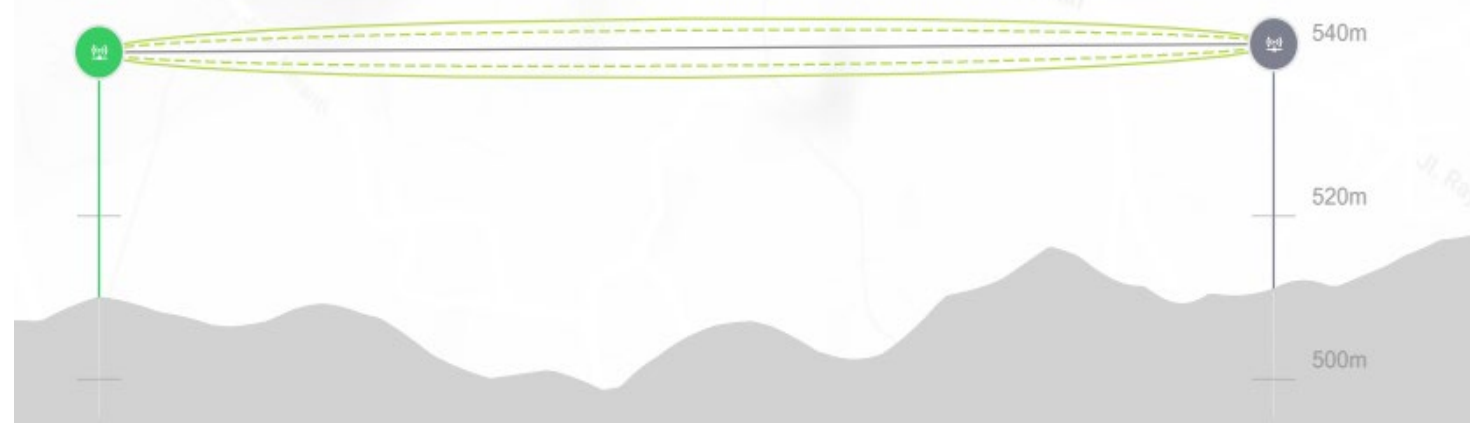

Figure 5. Ground contour site C - site D.

Table 1 shows the received signal each backhaul AP at the calculation. This result is based on the vendor calculator result with ideal condition.

Table 1. Received signal vendor online calculation.

\begin{tabular}{cccccc}
\hline No & AP Transmitter & AP Receiver & Distance & Received Signal & Data Rate \\
\hline 1 & Site A & Site B & $1,75 \mathrm{~km}$ & $-71.28 \mathrm{dBm}$ & $151.21 \mathrm{Mbps}$ \\
2 & Site B & Site C & $1.34 \mathrm{~km}$ & $-59.99 \mathrm{dBm}$ & $189.01 \mathrm{Mbps}$ \\
3 & Site C & Site D & $877.69 \mathrm{~m}$ & $-56.3 \mathrm{dBm}$ & $226.81 \mathrm{Mbps}$ \\
\hline
\end{tabular}

\section{Result and Analysis}

When installing the Access Point for backhaul and ground service at field test, measurements of the received signal strength at several different distances for the Ubiquity Nanostation Loco M5 device were also carried out. Table 2 shows the signal strength measurement at field test. Then, after successfully configuring and connect rach site of backhaul AP, we could find the Signal to Noise Ratio (SNR) value at Administrator Dashboard.

Table 2. SNR backhaul.

\begin{tabular}{cccc}
\hline No & Backhaul AP Location & Backhaul AP Distance & SNR Link \\
\hline 1 & Site A - Site B & $1.75 \mathrm{~km}$ & 42 \\
2 & Site B - Site C & $1.34 \mathrm{~km}$ & 37 \\
3 & Site C - Site D & $877.69 \mathrm{~m}$ & 39 \\
\hline
\end{tabular}

The SNR value for the $5 \mathrm{GHz}$ frequency in field test location ranges on the WLAN 802.11n backhaul link ranges from $37 \mathrm{~dB}$ to $42 \mathrm{~dB}$. Suppose we refer to the standard best practices, we can conclude that the average SNR value on the WLAN Backhaul infrastructure in the field test location is in good condition with the specifications of the ubiquity of two spatial streams, MCS 15 and channel width $40 \mathrm{Mhz}$ [5].

On the other hand, the measurement of the $2.4 \mathrm{GHz}$ access point for ground access has been done and the results are shown in Table 3. 
Table 3. Ground access AP measurement.

\begin{tabular}{ccccc}
\hline $\begin{array}{c}\text { AP Height from } \\
\text { Ground }(\mathrm{m})\end{array}$ & $\begin{array}{c}\text { Distance from } \\
\text { Tower }(\mathrm{m})\end{array}$ & Max. Signal & Link Speed AP & Max. Latency AP \\
\hline 40 & 5 & $-69 \mathrm{dBm}$ & - & - \\
30 & 5 & $-63 \mathrm{dBm}$ & $24 \mathrm{Mbps}$ & $61 \mathrm{~ms}$ \\
30 & 20 & $-71 \mathrm{dBm}$ & $12 \mathrm{Mbps}$ & $70 \mathrm{~ms}$ \\
10 & 5 & $-60 \mathrm{dBm}$ & $72 \mathrm{Mbps}$ & $14 \mathrm{~ms}$ \\
10 & 20 & $-65 \mathrm{dBm}$ & $65 \mathrm{Mbps}$ & $8 \mathrm{~ms}$ \\
10 & 25 & $-67 \mathrm{dBm}$ & $57 \mathrm{Mbps}$ & $24 \mathrm{~ms}$ \\
10 & 35 & $-72 \mathrm{dBm}$ & $43 \mathrm{Mbps}$ & $30 \mathrm{~ms}$ \\
10 & 73 & $-75 \mathrm{dBm}$ & $28 \mathrm{Mbps}$ & $102 \mathrm{~ms}$ \\
\hline
\end{tabular}

Throughput cannot be measured because the $2.4 \mathrm{GHz}$ AP is not connected to the server because it uses existing AP devices in the Tower when testing coverage. The Table 3 shows that the client at the ground can not connect to the $2.4 \mathrm{GHz}$ access point when the access point's height is 40 meters. The best height for a $2.4 \mathrm{GHz}$ access point is at a 10 -meter tower which can reach a 73 meter user distance from the Tower.

Table 4. AP Backhaul receive signal.

\begin{tabular}{cccc}
\hline Site & Tx Rate & Rx Rate & Receive Signal \\
\hline A - B & $6.5 \mathrm{Mbps}$ & $108 \mathrm{Mbps}$ & $-62 \mathrm{dBm}$ \\
B - C & $243 \mathrm{Mbps}$ & $216 \mathrm{Mbps}$ & $-65 \mathrm{dBm}$ \\
C - D & $162 \mathrm{Mbps}$ & $243 \mathrm{Mbps}$ & $-62 \mathrm{dBm}$ \\
\hline
\end{tabular}

In the Table 4, receive signal between hop is different from the P2P vendor link calculation results. That could be happened because of the interference channel at $5 \mathrm{GHz}$ frequency in the field test. In the backhaul network test, we locate a server at sites A, B, and C. To test the network performance at the backhaul network, we used the speed test tools and sent ICMP packets using the PING command inter backhaul AP. Table 5-7 are the test result of the network performance.

Table 5. Speed test result multihop backhaul AP.

\begin{tabular}{ccccc}
\hline Client Site & Server Site & Tx & Rx & Total \\
\hline B & A & $3.48 \mathrm{Mbps}$ & $5.73 \mathrm{Mbps}$ & $9.21 \mathrm{Mbps}$ \\
C & A & $0.97 \mathrm{Mbps}$ & $7.34 \mathrm{Mbps}$ & $8.31 \mathrm{Mbps}$ \\
C & $\mathrm{B}$ & $46.73 \mathrm{Mbps}$ & $55.34 \mathrm{Mbps}$ & $102.07 \mathrm{Mbps}$ \\
D & $\mathrm{A}$ & $0.58 \mathrm{Mbps}$ & $4.16 \mathrm{Mbps}$ & $4.74 \mathrm{Mbps}$ \\
D & $\mathrm{B}$ & $2.85 \mathrm{Mbps}$ & $14.79 \mathrm{Mbps}$ & $17.64 \mathrm{Mbps}$ \\
D & $\mathrm{C}$ & $0.32 \mathrm{Mbps}$ & $22.17 \mathrm{Mbps}$ & $22.49 \mathrm{Mbps}$ \\
\hline
\end{tabular}

Table 6. Ping test between backhaul AP.

\begin{tabular}{ccccc}
\hline Client Site & Server Site & Min Latency & Average Latency & Max Latency \\
\hline B & A & $1.799 \mathrm{~ms}$ & $6.2 \mathrm{~ms}$ & $19.894 \mathrm{~ms}$ \\
C & A & $2.747 \mathrm{~ms}$ & $7.39 \mathrm{~ms}$ & $18.995 \mathrm{~ms}$ \\
C & B & 1,458 & $2.3 \mathrm{~ms}$ & $3.487 \mathrm{~ms}$ \\
D & A & $5.445 \mathrm{~ms}$ & $8.79 \mathrm{~ms}$ & $18.64 \mathrm{~ms}$ \\
D & B & $2.992 \mathrm{~ms}$ & $4.5 \mathrm{~ms}$ & $8.799 \mathrm{~ms}$ \\
D & C & $1.54 \mathrm{~ms}$ & $2.5 \mathrm{~ms}$ & $3.153 \mathrm{~ms}$ \\
\hline
\end{tabular}


Table 7. Iperf test backhaul bandwith.

\begin{tabular}{ccc}
\hline Site & UDP & TCP \\
\hline A - B & $1,05 \mathrm{Mbps}$ & $4,82 \mathrm{Mbps}$ \\
A - C & $1,05 \mathrm{Mbps}$ & $3,36 \mathrm{Mbps}$ \\
A - D & $1,04 \mathrm{Mbps}$ & $1,26 \mathrm{Mbps}$ \\
\hline
\end{tabular}

The throughput test at the testbed location above is carried out directly by connecting via LAN to the backhaul device instead of measuring the access device due to the access device's availability at the time of testing. A network latency of $500 \mathrm{~ms}$ on the network infrastructure (VSAT Propagation delay) causes TCP throughput to degrade drastically. In contrast, UDP throughput does not experience a significant decrease; the value of the decline is only around 0.01 Mbps and can be ignored. That is consistent with the theory that UDP is not affected by network latency.

To test the network's service performance, we used HTTPERF to measure the response HTTP request and Wireshark to measure the quality of Voice Over IP Traffic.

Table 8. HTTP response time.

\begin{tabular}{cc}
\hline Site & Response Time \\
\hline B -> Server (site A) & $1.7 \mathrm{~s}$ \\
C -> Server (site A) & $1.8 \mathrm{~s}$ \\
D -> Server (site A) & $3.7 \mathrm{~s}$ \\
\hline
\end{tabular}

Based on Table 8, the lowest HTTP response time was 1.7 seconds, and the highest was 3.7 seconds. Based on the ITUT G.1010 standard [7], the web browsing user expectations preferred less than 2 seconds and acceptable is less than 4 seconds. So, the quality of service for HTTP browsing is preferred.

Table 9. VoIP quality of service.

\begin{tabular}{cccc}
\hline Site & Avg. Response Time & Avg. Jitter & Packet Loss \\
\hline B - > Server (site A) & $19.97 \mathrm{~ms}$ & $4.65 \mathrm{~ms}$ & $0 \%$ \\
C -> Server (site A) & $19.98 \mathrm{~ms}$ & $1.68 \mathrm{~ms}$ & $0 \%$ \\
D -> Server (site A) & $19.98 \mathrm{~ms}$ & $1.23 \mathrm{~ms}$ & $0 \%$ \\
\hline
\end{tabular}

Table 9 shows the Voice over IP (VoIP) service quality test, the highest jitter is $4.65 \mathrm{~ms}$, and the lowest is $1.23 \mathrm{~ms}$. The highest jitter is in the first hop. The high jitter is most likely due to the occurrence of quite a lot of co-channel interference. It can also be seen in table 2 that the Tx and RX between sites A and B are very low. The maximum jitter value should be $30 \mathrm{~ms}$, so we can conclude that the local VoIP service jitter quality test results are excellent. Based on ITUT G.1010 [7], the preferred key value of latency is $150 \mathrm{~ms}$. In the test results, network latency between multihop access point has a maximum value of 19,894 ms, and also in the VoIP test, the average response time is $19.97 \mathrm{~ms}$. This result means that the latency obtained can be categorized as preferred VoIP services based on ITUT G.1010 in the local network. In addition, VoIP server located on the internet will degrade the performance of packet latency because of network latency of $500 \mathrm{~ms}$ on the network infrastructure (VSAT Propagation delay).

\section{Conclusion}

A field case study in a rural area to expand the internet service area from VSAT terminals to 3 sites with a maximum distance of 3968 meters has been successfully carried out with multihop wireless network topology using $5 \mathrm{GHz}$ WLAN $802.11 \mathrm{n}$ on backhaul and $2.4 \mathrm{GHz}$ as client access. Based on the existing standards, internet services using multihop wireless network topology using $5 \mathrm{GHz}$ WLAN $802.11 \mathrm{n}$ on backhaul and $2.4 \mathrm{GHz}$ as client access methods are feasible. The quality 
still meets the key-value performance criteria from ITU-T. The best height for a $2.4 \mathrm{GHz}$ access point is at a 10-meter tower which can reach a 73-meter client smartphone distance from the Tower. The local VoIP network latency between multihop 5GHz WLAN access point has a maximum value of $19.894 \mathrm{~ms}$ and the maximum jitter $4.65 \mathrm{~ms}$. This result means that this network topology can deliver preferred VoIP services based on ITUT G.1010.

\section{References}

[1]. Zaidi Z, Lan K-c."Wireless Multi-Hop Backhauls for Rural Areas: A Preliminary Study," Journal of PLoS ONE 12(4): e0175358, 2017.

[2]. Zaidi Z, "Reliability of WiFi multi-hop backhaul connections for rural areas," Wireless Communications and Networking Conference (WCNC), IEEE. p. 2387-2392, 2013.

[3]. Bruce Alexander, 802.11 Wireless Network Site Surveying and Installation (Networking Technology), Cisco Press, 2004.

[4]. Jack Unger, Deploying License-Free Wireless Wide-Area Networks (Networking Technology) (1st. ed.), Cisco Press, 2008.

[5]. Ubiquity, Datasheet Nanostation M Nanostation Loco M. [Online]. Available: https://dl.ubnt.com/datasheets/nanostationm/nsm_ds_web.pdf.[Accessed: 16-Dec-2020].

[6]. Iskandar, Propagasi Sistem Komunikasi Bergerak, Institut Teknologi Bandung, 2015

[7]. International Telecommunication Union, "G.1010: End-user multimedia QoS categories".[Online]. Available: https://www.itu.int/rec/T-REC-G.1010-200111-I,2001 .[Accessed: Nov 2, 2021]. 